R O C ZNIKI HUMAN IS T Y C Z N E

Tom LXVIII, zeszyt 5 - 2020

ZESZYT SPECJALNY / SPECIALE UITGAVE

DOI: http://dx.doi.org/10.18290/rh20685sp-12

MURIEL WATERLOT

\title{
HOE TOLERANT IS HET VREEMDETALENONDERWIJS JEGENS VERTALEN?
}

\begin{abstract}
A b stract. Het doel van dit artikel is na te gaan of vertalen tegenwoordig al dan niet getolereerd wordt in het vreemdetalenonderwijs. Om deze vraag te beantwoorden zullen we eerst stilstaan bij de argumenten van de tegenstanders van het vertalen. Daarna zullen we aan de hand van een bondig historisch overzicht van de evolutie van de verschillende taalleermethodes en benaderingen de oorzaken van deze intolerante houding verklaren. Daarna laten we enkele prominente didactici aan het woord die argumenteren dat het vertalen onterecht uit het vreemdetalenonderwijs werd verbannen. Tot slot blijven we stilstaan bij het Europees Referentiekader voor Moderne Vreemde Talen: Leren, Onderwijzen, Beoordelen (ERK) (2008) dat aan het begin van de $21^{\mathrm{e}}$ eeuw voor het vertalen de notie 'bemiddeling' introduceerde in de context van de bevordering van het taalleren in een multilinguïstisch en muliticultureel Europa. Op basis hiervan zullen we enkele bedenkingen formuleren aangaande de huidige positie van het vertalen in het vreemdetalenonderwijs.
\end{abstract}

Trefwoorden: T2-vertaling; vreemdetaalonderwijs (vto); vertaaldidactiek; taalonderwijs; taaldidactiek.

\section{INLEIDING}

De controverse rond de toepassing van het vertalen in het vreemdetalenonderwijs (hierna afgekort als vto) heeft een lange geschiedenis en is tot op vandaag nog niet volledig verdwenen. De intolerantie tegenover vertalen verscheen voor het eerst aan het eind van de $19^{\mathrm{e}}$ eeuw toen de grammaticavertaalmethode haar dominante positie verloor.

Dr. habil. Muriel Waterlot is Adiunkt (Universitair Hoofddocent) bij de Katedra Języka Niderlandzkiego (Vakgroep voor Nederlandse Taal) van het Instituut Taalkunde bij de Katolicki Uniwersytet Lubelski Jana Pawła II (Katholieke Universiteit van Lublin). Zij houdt zich vooral bezig met didactiek van het Nederlands als vreemde taalin het hoger onderwijs en het benutten van vertalen en tolken in deze didactiek. Correspondentieadres: Katedra Języka Niderlandzkiego IJ WNH, Katolicki Uniwersytet Lubelski, Al. Racławickie 14, 20-950 Lublin, Polen; e-mail: murielwaterlot@kul.pl. ORCID: https://orcid.org/0000-0002-1665-2543 
Omdat met de opkomst van de communicatieve methode in de jaren ' 70 het debat rond het vertalen in het vto opnieuw op de voorgrond trad, besloot ik te onderzoeken wat de huidige positie is van het vertalen in het vto en of de houding van didactici nog steeds zo intolerant is.

In dit artikel zullen we eerst aan de hand van een literatuuronderzoek nagaan wat de argumenten tegen het vertalen in het vto zijn. Daarna zullen we achterhalen hoe vertalen als didactische activiteit kan worden ingezet in dit soort taalonderwijs en welke werkvormen er gebruikt kunnen worden. Verder blikken we terug op de geschiedenis van de methoden en benaderingen die voor het vto werden ontwikkeld van de $18^{\mathrm{e}}$ tot de $20^{\mathrm{e}}$ eeuw om te onderzoeken waar die intolerante houding van taaldidactici vandaan komt, en of dit een algemene trend was.

Om de centrale vraag van dit onderzoek te beantwoorden, zullen we tot slot aan de hand van enkele recente publicaties onderzoeken hoe het tegenwoordig gesteld is met de integratie (tolerantie) van het vertalen in het vto.

\section{ARGUMENTEN TEGEN VERTALEN \\ IN HET VREEMDETALENONDERWIJS}

Voor zover kon worden achterhaald, werd in de $20^{\mathrm{e}}$ en $21^{\mathrm{e}}$ eeuw door Nederlandstalige taaldidactici geen expliciet onderzoek verricht naar de rol van vertalen in het Nederlands als vreemde taal (hierna afgekort als nvt) of als tweede taal ${ }^{1}$. Dit wordt bevestigd door Jane Fenoulhet die in haar artikel Vertalen als didactische werkvorm opmerkt dat er in het vreemdetalenonderwijs sprake is "van een gebrek aan behandelingen van ons [dit] onderwerp in de literatuur over het vto" (Fenoulhet 41). Dit gebrek blijkt tegenwoordig nog steeds actueel te zijn wat het Nederlands betreft. Vandaar dat we ons in dit artikel zullen concentreren op de Engelstalige literatuur die heel wat informatie bevat over de hantering van deze werkvorm in het vto. Omwille van de onmiskenbare invloed van de trends van de Angelsaksische didactiek op het onderwijs van het Nederlands als vreemde taal (nvt), presenteren we hieronder - op basis van de gegevens verzameld door Constanza Peverati (8) - een overzicht van de belangrijkste argumenten van de tegenstanders:

\footnotetext{
${ }^{1}$ In dit artikel zullen we gemakshalve gebruik maken van de afkorting nvt om te verwijzen naar het onderwijs van het Nederlands als vreemde taal en als tweede taal.
} 
- vertalen is een 'afgezonderde activiteit' (cfr. 'a solitary activity');

- vertalen is een onafhankelijke vaardigheid waarvan de aard grondig verschilt van de vier basisvaardigheden die iemands taalkennis bepalen. Bijgevolg mag het niet worden aangewend om een van deze vier vaardigheden te onderwijzen;

- vertalen neemt veel tijd in beslag waardoor er minder tijd overblijft voor het onderwijs van de vier vaardigheden;

- vertalen is onnatuurlijk;

- vertalen wekt bij de leerders de schijn van een een-op-een-correspondentie van uitdrukkingen in twee talen;

- vertalen belet studenten te denken in de vreemde taal (T2);

- vertalen werkt interferentie en negatieve transfer in de hand;

- vertalen is een slechte manier om de taalvaardigheid van taalleerders te toetsen;

- vertalen belet de studenten zich op een vrije manier uit te drukken;

- vertalen belemmert de verwezenlijking van de algemeen aanvaarde doeleinden van het vto (Peverati 8; eigen vertaling - M.W.).

Ook al vinden we in de Nederlandstalige literatuur geen uitgebreide analyses over de rol en positie van vertalen in het vto, treffen we er gegevens aan uit de praktijkervaring van enkele vreemdetaaldocenten, zoals Jane Fenoulhet, Claudia Huisman en Ingrid Degraeve. Omdat het hier vooral om positieve aspecten van het vertalen gaat, komen we hierop terug onder punt 5 .

\section{HOE KAN VERTALEN WORDEN INGEZET IN HET VREEMDETALENONDERWIJS}

Uit recente wetenschappelijke publicaties betreffende de vertaaldidactiek kunnen we opmaken dat vertalen in het onderwijs op twee manieren een rol vervult. Enerzijds wordt vertalen nu al sinds eeuwen gebruikt "als methode bij het onderricht van vreemde talen en als middel om vorderingen van leerlingen in taalverwerving te controleren" (Holmes 185). Dit soort van vertalen wordt onderzocht en toegepast in het taalonderwijs en wordt in het Engels pedagogical translation genoemd (wat in het Nederlands kan worden vertaald door 'pedagogisch vertalen') (Carreres, "Translation" 123). Anderzijds wordt vertalen gedoceerd in instituten en cursussen ter opleiding van beroepsvertalers. Deze recentere vorm van vertaalonderwijs die toegepast 
wordt in de vertalersopleiding en een tak vormt van de toegepaste vertaalwetenschap, wordt in de zogenaamde 'map' van Holmes ${ }^{2}$ aangeduid met Translator Training (cfr. figuur 1). In dit soort van vertaalonderwijs (= het professionele vertaalonderwijs) spreekt men eerder van de 'pedagogiek van het vertalen' (in het Engels: pedagogy of translation) (Carreres, "Translation" 123).

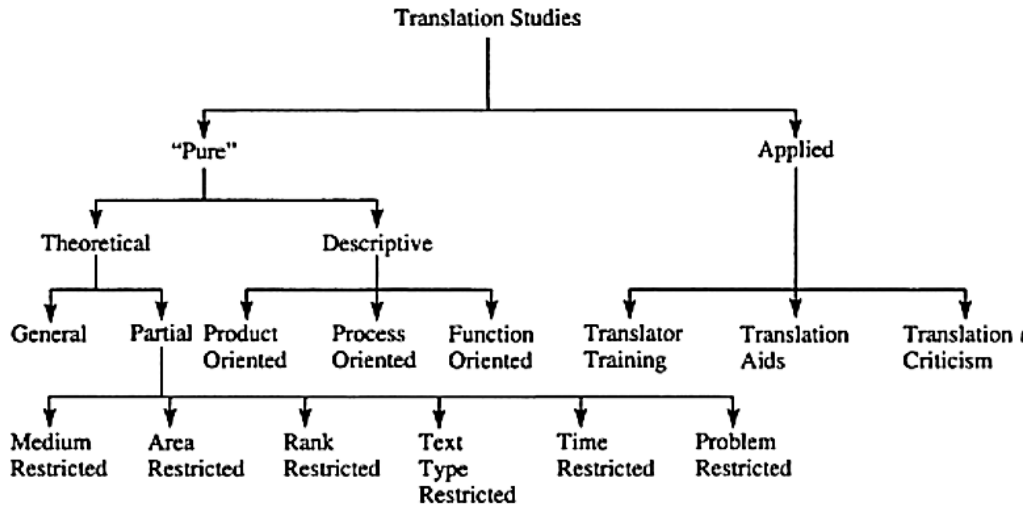

Figuur 1. 'Map' van Holmes voor de vertaalwetenschap door Toury (1995) (uit: The Routledge Encyclopedia of Translation Studies 278)

In het vto verwijst het 'pedagogisch vertalen' naar de toepassing van vertalen als een middel of instrument om de linguïstische, interlinguïstische en interculturele competentie van leerders te bevorderen in andere domeinen dan de vertaalwetenschap (González-Davies 9). Het verschil tussen beide komt goed naar voren in de titel van een artikel van Angeles Carreres ("Translation"): Translation as a means and as an end oftewel "vertalen als middel en vertalen als doel op zich'.

Wanneer we vertalen gebruiken als werkvorm in de taalles kunnen we een onderscheid maken tussen formeel en informeel vertalen. Met formeel vertalen bedoelen we het voorleggen van een stuk tekst of zinnen aan de leerders waarvan zij een geschreven vertaling moeten produceren. Met informeel vertalen worden alle andere vormen bedoeld, van het overbrengen van geschreven en gesproken vormen van $\mathrm{T} 1$ in $\mathrm{T} 2$ en andersom, voornamelijk mondeling maar ook geschreven. Verder kunnen we ook een onderscheid maken tussen de vertaling van (1) teksten die min of meer een geheel vor-

\footnotetext{
${ }^{2}$ Holmes heeft zelf geen schematische voorstelling gemaakt van de vertaalwetenschap. In de vertaalwetenschap wordt dus vaak verwezen naar Toury's schematische voorstelling (vergelijk figuur 1) die hij maakte op basis van Holmes' terminologie en omschrijving van het vak.
} 
men en (2) het vertalen van losse zinnen of woorden. Bij het eerste en het tweede kan zowel formeel als informeel te werk worden gegaan: denken we bijvoorbeeld aan de lege plekken naast de woorden in leerboeken waar studenten hun eigen vertalingen invullen.

\section{BEKNOPT HISTORISCH OVERZICHT VAN DE TAALMETHODES- EN BENADERINGEN VAN DE $18^{\mathrm{E}}$ EEUW TOT DE $20^{\mathrm{E}}$ EEUW - OORZAKEN VAN INTOLERANTIE JEGENS VERTALEN}

In onze Europese beschaving is de oudste vorm van vreemdetalenonderwijs het onderwijs in de klassieke talen, vooral het Latijn. Latijn was namelijk ongeveer tweeduizend jaar lang de taal van religie, wetenschap en cultuur. Het duurde echter tot de tweede helft van de $19^{\mathrm{e}}$ eeuw voordat de 'moderne' vreemde talen naast de 'klassieke' talen een vaste positie kregen in het onderwijs (Kwakernaak 130). Ook al hoeven het Frans, het Duits en het Engels in Europa geen concurrentie meer te vrezen van het Latijn, wordt nog steeds de term 'moderne' vreemde talen gebruikt.

De negentiende-eeuwse (Nederlandse) vreemdetaaldocenten volgden zoveel mogelijk het voorbeeld van hun collega's van de klassieke talen, omdat hun vak, om in aanzien te staan, wetenschappelijk gefundeerd moest zijn. In de klassieke talenstudie, meer bepaald in de Latijnse scholen, had zich na de middeleeuwen de grammatica-vertaalmethode ontwikkeld.

In deze methode stond het bestuderen van (losse) woorden centraal, en in een aantal formele grammaticalessen maakten taalleerders kennis met de regels van de syntaxis en morfologie van de vreemde taal. Aanhangers van deze methode waren ervan overtuigd dat de bestudering van regels en woordenlijsten leidt tot het leren van de taal. Doordat het accent van deze benadering vooral op het schriftelijke taalgebruik lag, kwamen mondelinge vaardigheden in deze methode vrijwel niet aan bod. Het leren van de taal was voornamelijk een middel om (literaire) teksten te kunnen lezen.

De vertaalmethode verloor haar dominante positie, voornamelijk omdat het gebruikelijke repertoire van spreekvaardigheidsoefeningen (dat enkel spreekbeurtopdrachten en voorleesoefeningen omvatte) niet voorzag in oefeningen die afgestemd waren op het voeren van een examengesprek over literatuur in de doeltaal. Vanuit de overtuiging dat het gebruik van de moedertaal en vertaaloefeningen de ontwikkeling van communicatieve en productieve vaardigheden belemmeren, werden vertaaloefeningen gebannen uit de 
taalles en werden voortaan methodes en benaderingen ontwikkeld die strikt eentalig waren en waarin invul-, omvorm- en vervangoefeningen ${ }^{3}$ werden $^{2}$ gebruikt.

De beweging (waarnaar ook in de Nederlandstalige wetenschappelijke literatuur wordt verwezen met de term 'Reformbeweging') die deze revolutie in het taalleren veroorzaakte, werd eind $19^{\mathrm{e}}$ eeuw op gang gebracht door Wilhelm Viëtor met zijn brochure Der Fremdsprachenunterricht muß umkehren! Ein Beitrag zur Überbürdungsfrage (1882). Hij riep op tot een hervorming die bestond uit een aantal voorstellen om de oude onderwijspraktijk te vervangen door een nieuwe waarbij onder meer mondelinge oefeningen in de vreemdetaalles ingevoerd werden. Dit had echter niet de uitsluiting van het vertalen tot gevolg, maar wel een wijziging in de mondelinge toepassing ervan:

The teacher should gloss any new words which cannot be made clear from the context, but he should leave the class to compete with suggestions for a complete translation under his guidance. (Howatt 360)

Aangezien de Reformbeweging pleitte voor taalgebruik en communicatie (geen taalkennis), onderwijs in de taal (en niet over de taal) en inductief le$\mathrm{ren}^{4}$, werd er minder beroep gedaan op vertalen. Vertalen werd dus niet volledig uitgebannen. Sommigen verdedigden zelfs de rol ervan, zoals Henry Sweet (1845-1912):

We translate the foreign words and phrases into our languages simply because this is the most convenient and at the same time most efficient guide to their meaning. (Sweet 202).

Volgens Sweet heeft het 'misbruik' van grammatica's en woordenboeken geleid tot de 'natuurlijke methode' (in het Engels natural method) die de manier nabootste waarop kinderen hun eerste taal leren. Hij geeft toe dat kinderen verschillen van vreemdetaalleerders. Bij het leren van een nieuwe taal gaan deze laatstgenoemden namelijk uit van hun eerste taal. Volgens hem hebben volwassenen bovendien een voordeel dat de kinderen niet heb-

\footnotetext{
${ }^{3}$ Omvormoefeningen worden ook 'transformatieoefeningen' genoemd. Een voorbeeld van een dergelijke oefening is het geven van zinnen met een opdracht als: 'Zet in de verleden tijd', 'Zet in het meervoud'. Een voorbeeld van een zogenaamde 'vervangoefening' is het vervangen van bepaalde woorden in een zin door een passend synoniem (Kwakernaak 209).

${ }^{4} \mathrm{Bij}$ inductief leren wordt de leerder geconfronteerd met een concreet verschijnsel (bijvoorbeeld een van de tijden van het werkwoord) en moet hij zoeken naar het systeem, de regel die erachter zit (Kwakernaak 290).
} 
ben: ze kunnen zich beroepen op hun analytisch vermogen en hun vermogen om te veralgemenen - andersgezegd: ze kunnen gebruik maken van een grammatica en een woordenboek. Volgens Sweet leidt het verbannen van het vertalen uit de vreemdetaalles niet tot het verdwijnen van associaties tussen de eerste taal en de vreemde taal. Die vinden volgens hem los van het vertalen ook plaats (Sweet 198). In The Practical Study of Languages heeft Sweet het over de twee vertaalrichtingen: van en uit de vreemde taal. In die context verschijnt voor het eerst het idee van vertalen in de communicatieve betekenis:

Translation from one language into another ought to imply as a matter of course that what is translated has a meaning (...) it is necessary that they [the sentences] should express something useful, something worth saying (...). (Sweet 204-205)

Uit dit citaat kunnen we opmaken dat het belang van de 'betekenis' lang voor het verschijnen van de communicatieve aanpak in de tweede helft van de twintigste eeuw werd benadrukt.

Aan het eind van de negentiende eeuw, met de komst van de directe (Direct Method) of natuurlijke methode (Natural Method), werd het gebruik van vertalen uiteindelijk 'verboden' in de taalles (Howatt 192).

Het debat rondom de integratie van het vertalen in het vto treedt opnieuw op de voorgrond met de opkomst van de communicatieve methode in de jaren '70. Wat het vertalen betreft, kan worden opgemerkt dat in die periode onderzoekers en taalpedagogen twee tegenstrijdige standpunten innamen. Enerzijds waren er diegenen die de communicatieve aanpak beschouwden als een soort van vervolg op de directe methode, waarin geen ruimte was voor vertalen dat niet als een authentieke activiteit beschouwd werd. Anderzijds waren er diegenen die voorstanders waren van vertalen in het vto. Zij beschouwden vertalen wél als een activiteit van het dagelijkse leven en zagen de meerwaarde ervan in de communicatieve functie die het kan vervullen. Een voorbeeld van een voorstander van het vertalen is Henry Widdowson, één van de meest vooraanstaande figuren uit de toegepaste taalkunde die over vertalen in het vto het volgende beweert:

What we are aiming to do is to make the learner conceive of the foreign language in the same way as a communicative activity. This being so, it would seem reasonable to draw upon the learner's knowledge of how his own language is used to communicate. This is to say, it would seem reasonable to make use of translation. (Widdowson 159 in Pym en Ayvazyan 10) 
Ook in de werken van andere auteurs, die gebaseerd zijn op de communicatieve aanpak, vinden we positieve uitspraken over het gebruik van T1 (of de moedertaal) en vertaaloefeningen in taalverwerving. Een voorbeeld hiervan zijn Mary Finocchiaro en Christopher Brumfit die het volgende beweren: "Judicious use of native language is accepted where feasible"; en over het gebruik van vertalen: "Translation may be used where students need or benefit from it" (Finocchiaro en Brumfit 92 in Ayvazyan 23).

Een ander voorbeeld is de uitspraak van Ian Tudor die over vertalen de volgende uitspraak deed:

Translation, as the process of conveying messages across linguistic and cultural barriers, is an eminently communicative activity, one whose use could well be considered in a wider range of teaching situations than may currently be the case. (Tudor in Duff 5)

In het docentenboek Translation van Alan Duff vraagt Alan Maley, de toenmalige directeur-generaal van de Bell Educational Trust in Cambridge, zich af of vertalen in de context van de communicatieve tendens dan toch een nuttige rol kan spelen in het vto:

Only recently, as the communicative movement has begun to run short of ideas, has there been a resurgence of interest in traditional practices such as translation. Could it be that it serves some useful purpose after all? Could it be renovated, humanized, made communicative? (Maley in Duff 3)

Op deze vraag formuleert Duff zelf het antwoord en definieert de rol van vertalen als volgt: "translation develops three qualities essential to all language learning: accuracy, clarity, and flexibility [...]" (Duff 7).

Uit dit historisch overzicht kunnen we dus afleiden dat de intolerantie tegenover vertalen hoofdzakelijk veroorzaakt werd door het feit dat het communicatieve aspect van vertalen werd verwaarloosd. Dit heeft ertoe geleid dat taaldidactici langzamerhand zijn beginnen te beseffen dat de houding tegenover vertalen in het taalleren herzien moest worden.

\section{POSITIE VAN HET VERTALEN \\ IN HET VREEMDETALENONDERWIJS IN DE $21^{\mathrm{E}}$ EEUW}

In antwoord op de noodzaak om de rol van vertalen te herdefiniëren, verschijnen in de $21^{\mathrm{e}}$ eeuw een aantal Engelstalige wetenschappelijke publica- 
ties waarin de communicatieve dimensie van het vertalen wordt benadrukt ${ }^{5}$. Een voorbeeld hiervan is het werk van Guy Cook waarin vertalen als een communicative activity of een 'communicatieve activiteit' wordt beschouwd die volgens hem strookt met de taakgerichte aanpak:

Such a use of translation has all the strengths and characteristics of the best communicative meaning-focused tasks, but with an extra dimension. And in the spirit of task-based teaching, it mimics real-world situations. (Cook 149).

Andere taalkundigen die het communicatieve aspect van vertalen als argument aanvoeren zijn González-Davies [in haar werk Multiple Voices in the Translation Classroom], Sara Laviosa en Juliane House [in haar boek Translation] die beiden op het belang ervan wijzen om vertalingen als communicatieve activiteiten in te bedden in (gesimuleerde) communicatieve situaties die relevant zijn voor de taalleerders.

De meest opmerkelijke ommekeer van de houding van taaldidactici tegenover vertalen als werkmethode werd echter teweeggebracht door de publicatie van het Gemeenschappelijk Europees Referentiekader voor Moderne Vreemde Talen: Leren, Onderwijzen, Beoordelen (ERK) van de Raad van Europa $(2001,2008)^{6}$. Het vertalen in het taalonderwijs wordt hierin niet alleen erkend, maar ook gestimuleerd. Hiervoor introduceert de Raad van Europa de notie bemiddeling. Dit vindt plaats in de context van de bevordering van het taalleren in een multilinguïstisch en muliticultureel Europa. Voortaan erkent de Raad - en bijgevolg ook beleidsmakers, uitgevers en certificerende instellingen - het vertalen als volwaardige taalactiviteit in het taalonderwijs dat als een didactisch instrument ingezet kan worden om de interculturele communicatie van de taalleerder te activeren en te bevorderen.

De term mediation of 'bemiddeling' werd met betrekking tot het vertaalonderwijs in feite voor het eerst in 1993 door Hans Heinrich Stern gebruikt (cfr. 'crosslingual mediation' oftewel 'cross-linguistische bemiddelingsactveiten' - zowel naar T1 als T2).

De notie wordt in het ERK in verband gebracht met de opbouw van een communicatieve competentie waarop iemand flexibel een beroep kan doen met het oog op een doeltreffende communicatie met een gesprekspartner.

\footnotetext{
${ }^{5}$ Voor zover kon worden achterhaald, bestaan er geen Nederlandstalige wetenschappelijke publicaties met betrekking tot dit soort onderzoek.

${ }^{6}$ Ondanks het feit dat het ERK een vrij abstracte beschrijving van beheersingsniveaus is en lang niet alle selectie- en ordeningsprincipes zijn opgelost, wordt het op grote schaal toegepast door beleidsmakers, uitgevers van leerboeken (vto en nt2) en certificerende instellingen.
} 
Deze competentie kan bevorderd worden door taalactiviteiten zoals 'receptie', 'productie', 'interactie' en 'bemiddeling' (in het Engels: 'mediation'). Onder dit laatste soort activiteiten rekent het ERK dus vertalen en tolken (ERK 2008 147).

'Bemiddelende activiteiten' worden gedefinieerd als activiteiten waarbij de taalgebruiker "niet bezig is met zijn of haar eigen betekenis uit te drukken, maar hij of zij eenvoudigweg optreedt als 'intermediair' tussen gesprekspartners die elkaar niet rechtstreeks kunnen verstaan - gewoonlijk (maar niet uitsluitend) sprekers van verschillende talen" (ERK 2008 83). Deze ruimere opvatting van vertalen wordt voortaan communicatieve vertaling genoemd en betreft dus één van de vaardigheden (vijfde vaardigheid) die de taalleerder moet verwerven om een polyglot te worden die niet alleen talen kent, maar ook in staat is om zich tussen de culturen van die talen te bewegen.

\section{VERTALEN IN HET ONDERWIJS}

VAN HET NEDERLANDS ALS VREEMDE TAAL

Zoals reeds in punt 1 werd vermeld, werd - voor zover kon worden achterhaald - geen uitgebreid en diepgaan onderzoek verricht naar de voor- en nadelen van het vertalen in het nvt-onderwijs. Niettemin vinden we in de Nederlandstalige wetenschappelijk literatuur enkele waardevolle artikelen waarin taaldocenten verslag uitbrengen van de toepassing van vertalen in hun praktische taalvaardigheidscolleges. Een eerste voorbeeld is Vertalen als didactische werkvorm (Londen) van Jane Fenoulhet die vier doelstellingen van vertalen in het vto definieert (Fenoulhet 45-46): (1) De studenten leren vertalen: ze heeft het hier niet over een opleiding tot vertalen, maar over het vertalen in beide richtingen tijdens de taallessen; (2) de algemene taalverwerving bevorderen: volgens Fenoulhet vinden studenten het leuk om te vertalen en zou er onderzoek moeten worden gedaan naar de manier waarop de lessen door leerders worden ervaren; (3) de betekenis van woorden in het geheugen van de student vastleggen: in deze context haalt ze de woorden van Ludo Beheydt aan die stelt dat vertalen de snelste manier zou bieden om aan de kern van een woordbetekenis te komen en om zijn eerste indrukken over de mogelijke betekenis van een nieuw, in een Nederlandstalige context aangeboden woord te bevestigen of te wijzigen; (4) inzicht geven in de zinsen tekstgrammatica van het Nederlands: bij de lectuur van een tekst zou in- 
formeel vertalen naar de moedertaal toe snel inzicht geven in 'probleemzinnen' of zinnen uit de zinsgrammatica die studenen nog niet helemaal onder de knie hebben.

In haar artikel Vertalen als didactische werkvorm (Straatsburg) brengt Claudia Huisman verslag uit van de manier waarop vertalen als didactische werkvorm toegepast wordt aan het Nederlands instituut te Straatsburg. Ze concludeert dat het een belangrijke rol speelt in de vreemdetaalverwerving doordat ,zowel spontaan, natuurlijk gebruik van de moedertaal als ook het vertalen met didactische doeleinden zeer nuttig blijken te zijn, enerzijds met het oog op grammaticale en lexicale oefening en consolidatie, anderzijds ter bevordering van vooral de receptieve vaardigheden" (Huisman 51). Volgens Huisman is er sprake van een come-back van de vertaling omdat het onmogelijk is om de moedertaal volledig uit te schakelen tijdens het proces van de vreemdetaalverwerving (48).

Een meer recent artikel over vertalen als werkvorm is dat van Ingrid Degraeve die vanuit haar praktijkervaring aantoont dat vertalen als hulpmiddel aangewend kan worden om de vier klassieke vaardigheden te oefenen, en om de interculturaliteit van de taalleerders te bevorderen via bijvoorbeeld de T1vertaling van literaire teksten of gedichten uit een taalleerboek waarin tegenwoordig dergelijke tekstsoorten opgenomen zijn. Via vertaaltaken kan bovendien het vertalen als vijfde vaardigheid geoefend worden (Degraeve 49). Ook in dit artikel worden geen tegenargumenten jegens vertalen in het vto genoemd. In haar artikel verwijst Degraeve naar Vertalen als hulpmiddel bij het literatuuronderwijs van Lut Missinne die beweert dat het vertalen van literaire teksten de taalkennis (woordenschat en grammatica) en taalverwerving in de hand werkt (Missine in Degraeve 48).

\section{CONCLUSIE}

In de context van het taalleren zien we dat we - zoals David Atkinson ooit meende - te maken hebben gehad met "a case in which the baby was indeed thrown out with the bathwater" (Atkinson 242 in Carreres, "Strange Bedfellows" 125). Aan de hand van dit literatuuronderzoek hebben we aangetoond dat in de $20^{\mathrm{e}}$ en $21^{\mathrm{e}}$ eeuw sommige taaldidactici hebben ingezien dat vertalen - indien op een andere manier toegepast dan in de grammaticavertaalmethode of bij wijze van aanvulling op een monolinguale methode de taalverwerving wel degelijk in de hand werkt en het op verschillende 
niveaus bevordert. Bijgevolg kunnen we concluderen dat sinds de grammatica-vertaalmethode de houding van taaldidactici jegens vertalen in het vto een radicale ommekeer ondergaan heeft en - onder invloed van de herdefiniëring van de functie ervan - is geëvolueerd in de richting van een herwaardering of grotere tolerantie. Deze tolerante houding wordt echter nog verhinderd door een gebrek aan grootschalig onderzoek naar de effecten van vertalen op het taalleerproces, en de vraag op welke manier vertalen kan worden toegepast in het vto.

Hoe het is gesteld met de positie van het vertalen in het nvt, kon slechts gedeeltelijk worden achterhaald door de afwezigheid van grootschalig en diepgaand onderzoek. Niettemin kwamen we op het spoor van enkele artikelen waarin vreemdetaaldocenten vanuit hun praktijkervaring verslag uitbrengen van de doeltreffendheid van vertalen in het vto.

Rekening houdend met de onmiskenbare invloed van Anglosaksische opvattingen inzake didactiek en het feit dat uitgevers van leerboeken, beleidsmakers en certificerende instellingen rekening houden met de schalen van het ERK, is de kans groot dat ook het nvt in de toekomst evolueert in de richting van een grotere 'vertaaltolerantie'.

\section{BIBLIOGRAFIE}

Ayvazyan, Nune. Communicative Translation in Foreign-Language Teaching and Learning. Doctoral Thesis. Universitat Rovira i Virgili, Tarragona, 2017.

Carreres, Ángeles. "Strange Bedfellows: Translation and Language Teaching." Paper delivered at the Sixth Symposium on Translation, Terminology and Interpretation in Cuba and Canada, 1-21, 2006. CTTIC - Canadian Translators, Terminologists and Interpreters Council, cttic.org/ACTI/2006/papers/Carreres.pdf. Geraadpleegd op mei 2015).

Carreres, Ángeles. "Translation as a Means and as an End: Reassessing the Divide." The Interpreter and Translator Trainer, vol. 8, issue 1: Translation in the Language Classroom: Theory, Research and Practice, 2014, pp. 123-135.

Cook, Guy. Translation in Language Teaching. Oxford University Press, 2010.

Council of Europe. The Common European Framework of Reference for Languages: Learning, Teaching, Assessment. Strasbourg, Language Policy Unit, 2001.

Degraeve, Ingrid. "Literair vertalen en creatieve taalverwerving". Filter, vol. 19, nr 2, 2012, pp. 46-51.

Duff, Alan. Translation. Oxford University Press, 1989.

Fenoulhet, Jane. "Vertalen als didactische werkvorm (Londen)". Handelingen Tiende Colloquium Neerlandicum, red. Frida Balk-Smit Duyzentkunst, Piet de Kleijn, Theo Hermans, Internationale Vereniging voor Neerlandistiek, 1989, pp. 41-46. 
González-Davies, Maria. "Translation: Why the Bad Press? A Natural Activity in an Increasingly Bilingual World.” Humanising Language Teaching, vol. 9, no. 2, 2007, [s. p.].

Holmes, James. S. "Wat is vertaalwetenschap?" Denken over vertalen. Tekstboek vertaalwetenschap, red. Ton Naaijkens, Cees Koster, Henri Bloemen en Caroline Meijer, Nijmegen, Vantilt, 2004, pp. 149-161.

House, Juliane. Translation. Oxford University Press, 2009.

Howatt, Anthony Philip Reid. A History of English Language Teaching. Oxford University Press, 1984.

Huisman, Claudia. "Vertalen als didactische werkvorm (Straatsburg)". red. Frida Balk-Smit Duyzentkunst, Piet de Kleijn, Theo Hermans, Internationale Vereniging voor Neerlandistiek, 1989, pp. 47-51

Issues and Options in Language Teaching, red. Hans Heinrich Stern, Patrick Allen en Birgit Harley, $2^{\text {nd }}$ ed., Oxford University Press, 1993.

Kwakernaak, Erik. Didactiek van het vreemdetalenonderwijs. Bussum, Uitgeverij Coutinho, 2015.

Nederlandse Taalunie. "Gemeenschappelijk Europees: Referentiekader voor Moderne Vreemde Talen: Leren, Onderwijzen, Beoordelen. Common European Framework of Reference for Languages: Learning, Teaching, Assessment”. Taalunieversum.org, taalunie versum.org/ sites/tuv/files/downloads/gemeenschappelijk_europees_referentiekader.pdf. Geraadpleegd op 2 oktober 2018.

Newson, Dennis. "Translation and Foreign Language Learning”. Translation and Language Teaching: Language Teaching and Translation, red. Kirsten Malmkjaer, St. Jerome, 1998, pp. 63-68.

Peverati, Constanza. Translation in University Foreign-Language Curricula: An Analysis of Teachers' Attitudes, with Reference to Vocational and Transferability Criteria, Doctoral Thesis, Universitat Rovira i Virgili, Department of English and German Studies, Tarragona, www.tdx.cat/bitstream/handle/10803/292368/TESI.pdf?sequence=1 \&is Allowed=y. Geraadpleegd op 21.03.2017.

Pym, Anthony, en Nune Ayvazyan. "Linguistics, Translation and Interpreting in Foreign Language Teaching Contexts". The Routledge Handbook of Translation and Linguistics, red. Kirsten Malmkjær, Routledge, 2017. Digitale versie: usuaris.tinet.cat/apym/on-line/ trans lation/2016_transation_teaching_short.pdf. Geraadpleegd op 21.03.2017.

Taalunieversum.org, taalunieversum.org/onderwijs/termen/term/237/nvt/. Geraadpleegd op 20.05. 2017.

The Practical Study of Languages: A Guide for Teachers and Learners, red. Henry Sweet, New York, Henry Holt and Company, 1899/1900.

The Routledge Encyclopedia of Translation Studies, red. Mona Baker, Routledge, 1998.

Translation and Language Teaching. Language Teaching and Translation, red. Kristen Malmkjaer, St. Jerome Publishing, 1998. 


\section{TOLERANCJA W ZAKRESIE TŁUMACZENIA W GLOTTODYDAKTYCE}

\section{Streszczenie}

Zamierzeniem artykułu jest zbadanie, w jakim stopniu dydaktyka języków obcych (JO) w obecnych czasach nadal wykazuje się nietolerancją względem przekładu jako metody pracy dydaktycznej. W tym celu najpierw zostały omówione argumenty przeciwników translacji. Następnie, na podstawie historycznego przeglądu ewolucji różnych metod i podejść glottodydaktycznych naświetlono przyczyny tej nietolerancyjnej postawy. Na koniec zbadano, czy glottodydaktycy nadal są nietolerancyjnie nastawieni wobec tłumaczenia oraz czy nie mogłoby ono zostać zastosowane jako efektywny środek pomocniczy przy zdobywaniu poszczególnych umiejętności zalecanych przez Europejski System Opisu Kształcenia Językowego: uczenie się, nauczanie, ocenianie (ESOK).

Słowa kluczowe: tłumaczenia; nauczania języków obcych; dydaktyka przekładu; dydaktyka; glottodydaktyka.

\section{HOW TOLERANT IS FOREIGN LANGUAGE TEACHING TOWARDS TRANSLATION?}

\section{S u m m a ry}

The purpose of this article is to examine to what extent foreign language teaching is still intolerant towards translating as a working method. First, the author consider the arguments of the opponents of translation. On the basis of a historical overview of the evolution of various language learning methods and approaches, she then try to explain the intolerance towards translating. Finally, she determine whether the attitude of foreign language didacticians teaching in the $21^{\text {st }}$ century can be called 'tolerant', and whether the integration of translation and translation teaching can be used as an effective tool in acquiring specific skills in foreign language teaching.

Key words: Foreign Language Education (FLE); translation didactics; foreign language teaching; language teaching; didactics. 